\title{
PT3b Stage Finding
}

National Cancer Institute

\section{Source}

National Cancer Institute. pT3b Stage Finding. NCI Thesaurus. Code C48770.

A pathologic primary tumor TNM stage finding. The definition of pT 3b stage finding depends on the particular type of cancer that it refers to; for example, for cervical cancer, рT 3b stage finding is defined as follows:cancer extends to pelvic wall and/or causes hydronephrosis or nonfunctioning kidney; for kidney cancer, pT 3b stage finding is defined as follows: cancer with tumor grossly extending into the vena cava below the diaphragm. (from AJCC 7th Ed.) 